\title{
RACIONALIDADES CURRICULARES EN LA FORMACIÓN DEL PROFESORADO DE HISTORIA EN CHILE*
}

\author{
CURRICULAR RATIONALITIES IN THE TRAINING OF TEACHERS \\ SPECIALIZED HISTORY IN CHILE
}

\author{
Mario Valdés Vera ${ }^{* *}$ y Omar Turra-Díaz,***
}

\begin{abstract}
El artículo presenta resultados de una investigación que tuvo como objetivo indagar en las racionalidades curriculares predominantes en la formación de profesores de historia, desde los documentos FID (Formación Inicial Docente) y las voces de formadores que se desempeñan en universidades regionales del centro-sur de Chile. La investigación se realizó desde un paradigma comprensivointerpretativo, a base de un diseño de complementariedad metodológica que contempló la utilización del análisis de contenido y la teoría fundamentada como métodos de investigación. Los resultados muestran el predominio de una racionalidad curricular técnica, en tanto se establece como comprensiones fundamentales de la formación del profesorado, la centralidad del conocimiento disciplinar, el liderazgo docente en la distribución del conocimiento y una pasividad en su recepción por parte del estudiantado en formación, es decir, una relación pedagógica de carácter unidireccional.
\end{abstract}

Palabras claves: Racionalidades curriculares, profesorado de historia, formación inicial docente, racionalidad técnica.

This article presents the results of an investigation whose goal was to research the predominant curricula rationalities within training for History teachers, considering the Initial Teacher's Training documents ("FID”, Formación Inicial Docente) and the voices of professors who are currently teaching at regional universities in the central and south regions of Chile. The study was based on a comprehensive-interpretative paradigm, considering a methodological complementarity that use content analysis and a grounded theory as research methods. The results show that the curricular rational technique prevails, because it sets the content-centered knowledge, the teacher as someone who delivers knowledge and the passivity of students when receiving this knowledge as fundamental understandings of teacher's training, which means there is a unidirectional pedagogical relationship.

Key words: curricular rationalities, history teachers, initial teacher's training, technical rationality.

Desde inicios del presente siglo la formación inicial del profesorado se ha instalado como uno de los temas centrales y estratégicos de la agenda educativa en Chile, igual que en otros países de América Latina. Se reconoce en la formación docente un factor clave para el logro de aprendizajes en el estudiantado y para el mejoramiento del sistema educativo en general, según queda establecido en las páginas introductorias de los diversos programas de formación de profesores que se han implementado en Chile en los últimos quince años, y en los estándares orientadores para las carreras de pedagogía publicados por el Ministerio de Educación (Pedagogía en Educación Básica 2001; Pedagogía en Educación Media 2012). El interés por su mejoramiento se ha materializado en varios documentos ministeriales portadores de orientaciones y recomendaciones acerca de la Formación Inicial Docente (FID), que tienen como propósito actualizar y fortalecer su formación de manera de hacerlos protagonistas de un cambio educativo que se considera necesario y urgente. No obstante, la preocupación por la formación docente en el país se desarrolla en un contexto de crítica a la calidad de los programas y a sus continuas renovaciones curriculares sin evaluaciones previas, situación que impide ponderar debidamente sus fortalezas o debilidades. También se cuestiona la escasa articulación entre la formación pedagógica y la formación en la especialidad, la distancia entre el aprendizaje de contenidos curriculares y la comprensión de la naturaleza teórico-práctica de la acción pedagógica, la desvinculación de la formación inicial docente con el sistema escolar y con el trabajo docente en contexto (Comisión Formación Docente 2005; Ministerio de Educación [MINEDUC] 2006; Lara, Förster y Gorichon 2007). A lo anterior se suma el hecho de que en estos procesos de renovación de

\footnotetext{
* Resultado Proyecto Conicyt-Fondecyt 1151233.

** Universidad de Concepción. Concepción, Chile. Correo electrónico: mariovaldes@udec.cl

*** Universidad del Bío Bío. Chillán, Chile. Correo electrónico: oturra@ubiobio.cl
} 
la formación inicial no han sido consideradas las voces de sus protagonistas principales, el propio profesorado en ejercicio laboral (Ferrada y Turra 2012; Ferrada, Villena y Turra 2015).

Por su parte, la investigación respecto de la formación del profesorado se ha convertido en un ámbito de relevancia en el debate acerca del desarrollo profesional docente y en un campo de estudio estratégico para las definiciones de política pública. Si bien se trata de un objeto de estudio de reciente data en Chile, se evidencia un aumento sostenido de investigaciones que desde diversas perspectivas teóricas y empíricas reportan información concerniente al particular (Cisternas 2011). Respecto de la investigación de la formación del profesorado de historia, resulta evidente su desconsideración como objeto de estudio en el país. Uno de los pocos estudios existentes data del 2005 y es fruto de una tesis de doctorado (Vásquez 2005). Se trata de un estudio de alcance descriptivo, cuyo propósito fue conocer las características que ha tenido la formación inicial de profesores de historia en Chile, conocer las percepciones que tienen los docentes con dicha formación y de algunos aspectos de la reforma educativa de aquel entonces. Otro estudio que aporta tangencialmente a la temática es el de Santibáñez (2013), el que discute aspectos del ejercicio docente del profesorado en historia, interrogando la educación y la historiografía en relación con la reproducción de una ideología estatista, para aportar elementos de discusión a los procesos formativos del profesorado en la disciplina. En este contexto, se incorpora un estudio reciente de las racionalidades curriculares predominantes en la formación del profesorado de historia (Valdés 2017), de cuyo corpus extraemos algunos conceptos e información empírica. Por otro lado, la formación del profesorado de historia ha cobrado relevancia en Chile, debido al creciente interés y centralidad que ha tomado este campo disciplinar en el currículum escolar, principalmente por su carácter estratégico en la formación de las futuras generaciones de ciudadanos. Esto se comprende en el contexto de la importancia que adquieren ciertos ejes temáticos, habilidades y prácticas sociales que se promueven desde esta disciplina escolar, entre otras, la importancia del diálogo para la construcción de consensos, la aceptación de las diferencias culturales, políticas e ideológicas; la estimulación del pensamiento crítico como herramienta de desarrollo humano, el cultivo y potenciación de las habilidades de investigación, búsqueda y análisis de información, etc. No cabe duda que los nuevos requerimientos formativos escolares $-\mathrm{y}$ demandas sociales-reclaman una formación del profesorado de historia pensada desde una renovación pedagógica y disciplinar que supere los anclajes tradicionales de la formación positivista. Pero no sabemos cómo estos nuevos programas formativos han contribuido a la introducción de actualizadas perspectivas pedagógicas y más específicamente qué racionalidades curriculares predominan tanto en los documentos FID como en las comprensiones que declaran los académicos formadores.

En este artículo pretendemos dar cuenta, a partir del constructo conceptual de la racionalidad curricular, las características que asume el conocimiento pedagógico en la formación del profesorado de historia. A la base de indagación en fuentes documentales ministeriales y en las voces de académicos formadores, se consideraron tres campos de significación respecto de los cuales es posible pesquisar las racionalidades curriculares: la concepción del conocimiento constitutivo de la formación inicial; la comprensión acerca del rol de los actores educativos en la producción/distribución de conocimiento y la comprensión respecto de la relación pedagógica entre los actores del proceso formativo.

\section{Marco Teórico}

Desde hace un buen tiempo, en el debate curricular existe consenso que el currículo es una construcción cultural que organiza un conjunto de intereses y prácticas educativas humanas. En tanto campo discursivo, teórico y práctico, el currículo puede comprenderse como modelos paradigmáticos o racionalidades de actuación, que comprenden formas de construir e interpretar el conocimiento, la sociedad y los sujetos que la componen, así como los fines y objetivos educativos. De esta manera, la teoría curricular contemporánea distingue tres racionalidades curriculares: la racionalidad curricular de carácter técnico, la práctica o praxiológica y la racionalidad curricular crítica. Este agrupamiento es propuesto por primera vez en 1987 por la pedagoga australiana Shirley Grundy (1991), quien, basándose en Habermas (1986), vincula los fundamentos de los intereses del conocimiento humano con los principios de la acción y la praxis curricular. Es posible destacar que la conceptualización propuesta por esta autora ha sido utilizada por diversos autores en Chile y en el extranjero (Ferrada 2004; Pascual 
2008; Magendzo 2008; Malagon 2008), dando sustento teórico a la mayoría de los trabajos referidos a la teoría del currículo, como a sus racionalidades, paradigmas y enfoques. Describiremos brevemente cada una de estas racionalidades propuestas por la autora en comento.

\section{Racionalidad curricular técnica}

Desde la lógica de las racionalidades técnicas del currículum los procesos formativos son vistos como una serie de mecanismos que, bajo procedimientos secuenciados, pretenden alcanzar los conocimientos que se establezcan como necesarios para desarrollar y reproducir en los estudiantes, y por tanto, en la sociedad. Dicho en términos de lo curricular, la formación de profesionales se convierte en una imposición de contenidos que no consideran los contextos ni entornos culturales y territoriales de los estudiantes (Ferrada 2004). En síntesis, desde las racionalidades técnicas de lo curricular se plantea la superioridad del conocimiento disciplinar de carácter positivo e ilustrado, supeditándose la teoría por sobre la realidad de los sujetos (Pascual 1998).

\section{Racionalidad curricular práctica}

Además, el interés práctico radica en la necesidad ya no -a diferencia del interés técnico- de controlar el medio, sino de buscar los mecanismos que permitan comprenderlo, de manera que permita a los sujetos interactuar con él. Así se configura un campo de conocimientos en que se privilegia la interpretación y comprensión (Grundy 1991). En este marco, la racionalidad práctica del currículum enfatiza centralmente la comprensión del proceso educativo. La reflexión acerca de la práctica formativa -al considerar su contexto de realización y las condiciones concretas en que se desarrolla el trabajo del profesor- es eje central de esta racionalidad (Gimeno 2002).

\section{Racionalidad curricular crítica}

El interés de carácter emancipatorio ha dado lugar a una racionalidad curricular crítica, que engloba a las prácticas pedagógico-formativas que tienden a la emancipación de los sujetos, liberándolos de sus falsas concepciones y perspectivas deformadas de la realidad. De este modo la acción pedagógica debe configurarse de manera libre y horizontal entre las personas involucradas en el proceso, quedando así como una responsabilidad individual y colectiva el alcanzar aprendizajes liberadores, fundados en la reflexión consciente de los sujetos respecto de sus condiciones sociohistóricas concretas. La práctica formativa, desde este horizonte teórico, se sostiene en el concepto de praxis pedagógica, es decir, en una relación permanente entre teoría y práctica, entre intención y realidad (Ferrada 2002). Las perspectivas críticas del currículum se entienden, también, como prácticas productoras de sentidos, identidades y jerarquías en los sujetos, cuestión que se constituye en un eje de análisis central a la hora de aquilatar la complejidad del fenómeno curricular (Da Silva 1998).

De esta manera, las racionalidades curriculares definen la naturaleza del conocimiento curricular, es decir, sus componentes epistemológicos. Cada una de estas racionalidades disputan el predominio en el campo del currículo y se expresan en conceptualizaciones diferentes y proyectan, también, entendimientos distintos respecto de la producción, interpretación y distribución del conocimiento, y las relaciones entre los actores educativos en los procesos de formación.

\section{Metodología}

La investigación se realizó desde un paradigma comprensivo-interpretativo, sobre la base de un diseño de complementariedad metodológica dentro de la investigación cualitativa. Esta metodología resulta pertinente al estudio por su intencionalidad de alcanzar comprensión de una realidad social determinada, a partir de las significaciones de los propios sujetos que participan del campo objeto de investigación (Rodríguez et al. 1999). La complementariedad metodológica está dada por la utilización de la investigación documental y la teoría fundamentada como métodos investigativos, que nos permitirá dar cuenta del objetivo del estudio: indagar en las racionalidades curriculares predominantes en la formación de profesores de historia, desde los documentos (FID) y las voces de formadores que se desempeñan en universidades regionales del centro-sur de Chile. En una primera fase investigativa se examinaron los documentos nacionales FID seleccionados para el efecto: a) Estándares de Desempeño para la Formación Inicial Docente Ministerio de Educación Chile (MINEDUC 2001); b) Estándares Orientadores para Carreras de Pedagogía 
en Educación Media (MINEDUC 2012). Ambos documentos son fundamentales para examinar las orientaciones y propuestas acerca del docente que se busca formar, y en sus declaraciones portan racionalidades curriculares que las movilizan. La técnica de producción de información utilizada en esta fase es el análisis cualitativo de contenido, porque permite:

\begin{abstract}
Reelaborar los datos brutos ya sea simplemente aglutinándolos en clusters o conjuntos homogéneos que agrupen material de similar sentido a través de pasos sucesivos hasta llegar a la conceptualización o regla descriptiva que justifique su agrupamiento (Cáceres 2003:57).
\end{abstract}

La segunda fase investigativa involucró sucesivos encuentros de dialógicos con docentes formadores que comprometieron su participación en el estudio. La búsqueda aquí es por acceder a las significaciones curriculares que poseen respecto de la formación del profesorado de historia. Los participantes del estudio fueron definidos de acuerdo con los siguientes criterios de inclusión: voluntariedad por participar de la investigación, docencia en el campo del currículum o asignatura afín en la formación de profesores de historia, tener como mínimo diez años de experiencia en la formación de profesores.

En la siguiente Tabla 1 se muestra información específica de los participantes:

La técnica de producción de información fue la entrevista semiestructurada, entendida como una conversación orientada por un guion de preguntas preestablecidas en función del objetivo del estudio. Sin embargo, este tipo de entrevistas permite la realización de preguntas emergentes que permiten aclarar o profundizar en los significados de los participantes. Las entrevistas fueron realizadas a los docentes participantes en sus espacios cotidianos de trabajo, en las universidades respectivas y en momentos previamente acordados con ellas y ellos.

Para el análisis de la información producida se utilizó el método de la teoría fundamentada, el que proveyó de procedimientos tendientes a analizar los datos e información de campo, principalmente el llamado proceso de codificación en su versión abierta y axial. El proceso de reducción de la información fue desarrollado con apoyo del software Atlas Ti, con el que se realizó el proceso de codificación abierta de párrafos e ideas que contenían sentidos comunes, para luego agrupar estos códigos y formar categorías de análisis expresadas en los resultados.

\section{Resultados}

Respecto de los conocimientos constitutivos de la formación inicial docente en historia, los documentos que regulan dicha formación enfatizan la necesidad de una adecuada formación en el campo de la disciplina del conocimiento que le corresponderá enseñar al futuro docente de esta especialidad. El conocimiento disciplinar claramente se constituye en base principal de la formación. Uno de los documentos consultados señala en primer lugar que el profesor debe tener un óptimo dominio de los "contenidos del campo disciplinario o área de especialización respectiva, con énfasis en la comprensión de los conceptos centrales de este campo y su modo de construcción" (MINEDUC 2001: 11). Tal idea es confirmada párrafos más adelante cuando, ya instalados en los criterios y estándares exigibles a los profesores, se plantea que el docente para conseguir un desempeño de calidad es necesario que "maneje los contenidos que le corresponde enseñar y sepa cómo progresa la ciencia en ese campo. Asimismo, es necesario que comprenda la estructura de la disciplina que imparte" (MINEDUC 2001: 20). Así, la presentación de estos estándares de la disciplina de la Historia se exponen

Tabla 1. Sujetos participantes en la investigación.

\begin{tabular}{llc}
\hline \multicolumn{1}{c}{ Institución Formadora } & \multicolumn{1}{c}{ Courses } & Años de experiencia en FID \\
\hline Universidad del Bío-Bío / Chile & $\begin{array}{l}\text { Currículum y evaluación educacional I-II } \\
\text { Teoría de la enseñanza-Gestión de proyectos } \\
\text { educativos-Currículum }\end{array}$ & 10 \\
Universidad de La Frontera / Chile & Currículum y evaluación & 15 \\
Universidad Austral de Chile / Chile & & 15 \\
\hline
\end{tabular}

Fuente: Elaboración propia. 
como una serie de conocimientos vinculados a lo específico de las disciplinas, a saber, el documento Estándares Orientadores para Carreras de Educación Media (MINEDUC 2012) -que define estándares de formación para el campo de los docentes de las diversas disciplinas escolares, uno de ellos en Historia, Geografía y Ciencias Sociales- señala claramente en uno de sus acápites disciplinares: "Comprende las características generales de los principales procesos de las sociedades americanas desde los pueblos originarios hasta fines de la Colonia" (MINEDUC 2012: 142). Por otro lado, desde la perspectiva de los académicos, podemos subrayar que estos manifiestan una gran valoración por los conocimientos relativos a los fundamentos y la naturaleza del conocimiento disciplinar. Es así como los formadores de profesores de historia, en su conjunto, manifiestan una inclinación a considerar que los conocimientos disciplinares en la especialidad son la base principal de la formación. De hecho lo manifiestan como un rasgo distintivo de la carrera de pedagogía en historia, la que se caracteriza por la centralidad del conocimiento disciplinar: "Yo pienso que es muy importante el conocimiento disciplinario, porque ya es una carrera compleja que integra varias disciplinas, eso le da una complejidad mayor, a diferencia de otras pedagogías en las que también me ha tocado hacer clases" (Académica 1). Visto de este modo, uno de los académicos participantes en el estudio plantea la importancia de conocer los fundamentos epistémicos de las disciplinas, para ello él organiza su forma de trabajo con los estudiantes:

Siempre parto [con] los estudiantes que les pregunto cuál es el nodo epistemológico de la historia. Los estudiantes dicen los hechos, lo que pasó, etc., y yo les aclaro que el nodo epistemológico de la historia es el tiempo, y en geografía el nodo epistemológico es el espacio (Académico 2).

Sin embargo -de acuerdo con lo señalado por los académicos- se agrega el campo de lo pedagógico como otra matriz importante en la formación del profesorado de historia. Existe consenso en señalar como relevante la integración y vinculación del conocimiento disciplinar con el conocimiento pedagógico. Esta emergencia de la integración disciplinar es ineludible en la formación del profesor de historia, el que, como hemos visto, debe tener una muy sólida formación del conocimiento disciplinar, "pero también debieran tener una sólida formación pedagógica" (Académica 1). Ante esto los académicos formadores se instalan desde la necesidad de hacer un esfuerzo de transposición del contenido disciplinar para transformarlo en conocimiento enseñable, como lo plantea con claridad uno de los profesores que actuaron en esta investigación, quien al referirse a los conocimientos disciplinares de la historia y la pedagogía en la formación del profesor, señala que ambos:

\begin{abstract}
No son dos compartimentos estancos, como ocurre en muchas partes en la formación inicial docente, uno de los problemas seculares que ha habido ha sido la disociación entre ambas disciplinas, en circunstancias que lo que hoy día se propone es la enseñanza del contenido o la transposición didáctica en su versión gala (Académico 2).
\end{abstract}

Constatamos así la declarada necesidad -por parte de los docentes universitarios que trabajan en la FID en historia- de integrar los campos disciplinar y pedagógico, valga señalar que esta integración se tiende a concebir como la transposición del saber sabio al saber enseñable, es decir, de transformar el contenido de la disciplina histórica en materias a enseñar. Otra de las dimensiones estudiadas desde las racionalidades curriculares tiene que ver con el rol de los actores educativos en la producción/ distribución de conocimiento. En este sentido, en uno de los textos oficiales estudiados -que orienta en la actualidad la política pública de formación de profesores de enseñanza media del país- podemos apreciar que los profesores de Historia, egresados de las aulas universitarias, deben alcanzar estándares de manejo disciplinar reflejados en: "sólidos conocimientos y habilidades en las áreas curriculares a enseñar y dominio de metodologías y recursos didácticos respecto de cómo estas se enseñan" (MINEDUC 2012: 10). Es decir, se manifiesta una centralidad del conocimiento disciplinar del profesor, no obstante, se apela al manejo de conocimientos didácticos respecto de la disciplina. El documento señalado expresa que los estándares:

Describen las capacidades que se espera tenga el egresado de Pedagogía en Historia, Geografía y Ciencias Sociales para enseñar el área y cumplir su propósito formativo, se incluye en esta sección todo aquello que 
dice referencia a 'saber la disciplina para enseñarla’ (MINEDUC 2012:135).

A este respecto la política pública de formación de profesores, en la primera versión de los estándares (MINEDUC 2001), manifiesta el requerimiento al profesor respecto de reinterpretar los conocimientos del contenido disciplinar asociado a la enseñanza. Aparece aquí la noción de reinterpretación, interpelando al profesor en términos de que es él quien debe reelaborar y resignificar los contenidos, de modo de transformarlo en experiencias significativas para sus estudiantes, "Para ello, el profesor necesita elaborar representaciones sobre la base de su propia comprensión de los contenidos, teniendo presente el conocimiento y la experiencia previa de los alumnos" (MINEDUC 2001:20).

Se enfatiza claramente que el profesor es quien posee los conocimientos académicos, los que, esta vez reinterpretados, se instalan por sobre los conocimientos del contexto del estudiante. En definitiva y a manera de corolario estamos entonces en la consideración del sujeto estudiante, como otro en quien se deben propiciar aprendizajes del conocimiento histórico, de modo que pueda aumentar su acervo cultural y el conjunto de información que posee. Para lo anterior se le debe proveer de instancias de aprendizaje que consideren básicamente, por sobre sus experiencias y necesidades -mencionadas tangencialmente en los textos que hemos venido refiriendo-, el contenido de la disciplina. Lo anterior se constituye en un requisito sine qua non para darle sentido al aprender. En síntesis, entonces, se vuelve a reiterar, como lo plantea de manera permanente la política pública de formación de profesores y de historia en particular, los aprendizajes y habilidades pensados y orientados a base de contenidos, información y conocimientos del profesor. Por otro lado, respecto de este punto y a partir de lo declarado por los académicos formadores, discutimos con ellos en torno a la función del profesor y del actor estudiante en la producción/ distribución de conocimiento. Situamos la reflexión con ellos en estos temas en el afán de caracterizar su comprensión respecto de la dinámica que adquiere el conocimiento, cómo se construye, quién lo porta y su distribución en los ambientes formativos. En primer término emerge una visión clara desde los académicos formadores de profesores de historia respecto del conocimiento, al decir que este es socialmente construido.
Hay una construcción social del conocimiento, claro que hay muchas perspectivas teóricas [...] la construcción histórica es colectiva, no es individual. [...] los actores contribuyen con su perspectiva a la construcción histórica, y las perspectivas de los distintos actores se va hilvanando, con dialéctica, con tensiones y con controversia interna; pero esa es la realidad, así es la realidad, llena de contradicciones (Académico 2).

Se hace referencia así a una de las propiedades del conocimiento disciplinar y social, y a su vez distintiva del conocimiento histórico: sus distintas y variadas interpretaciones. Lo anterior se instala por sobre cualquier valoración de la construcción o co-construcción de este conocimiento, es decir, la que se pueda realizar, potencialmente también, con los otros actores del proceso formativo. En el fondo, si bien se reconoce este origen colectivo y social del conocimiento, en sus fundamentos se mantiene la hegemonía del discurso disciplinar del contenido, esta vez destacándose su potencial multiplicidad de interpretaciones. Por otra parte y respecto de la distribución del conocimiento, aquí nuevamente el docente adquiere un rol fundamental. Este rol se define por dos conceptos muy presentes en el leguaje pedagógico de cuño tecnocrático, a saber, gestión y liderazgo en la producción y circulación del conocimiento. Como es expresado por una de las docentes formadoras, quien se refiere a la producción de conocimiento en su trabajo formativo:

Hay mucha gestión del profesor, hay mucho liderazgo, hay mucha tarea previa, porque él genera el material con el cual interactuar; él propicia esa dinámica y tiene que convencer a un grupo de que se puede [...] por eso digo el 'liderazgo'. Hay que convencer a un grupo de que juntos pueden aprender (Académica 1).

Es muy interesante ahondar en estas propiedades del conocimiento y de la manera cómo es concebido desde la opinión de esta académica. Apreciamos la distancia que se propone entre lo que es necesario aprender, en el marco de la preparación de material, la motivación extrínseca al estudiante, y su papel en el convencer a los estudiantes de su rol en el aprendizaje. Llama la atención que este proceso de distribución del 
conocimiento se desarrolle-como podría leerse-de modo unilateral y con un rol anclado en la pasividad del estudiante, versus el liderazgo del profesor. Otra de las dimensiones importantes de nuestra búsqueda respecto de las racionalidades curriculares tiene que ver con la comprensión que poseen los académicos respecto de la relación pedagógica entre los actores del proceso formativo. En este punto los hallazgos muestran que la mayoría de los profesores formadores declara establecer relaciones dialógicas y participativas con sus estudiantes de pedagogía en historia. De esta forma lo describe uno de nuestros participantes en la investigación: "mi relación con los estudiantes la definiría como muy horizontal. En primer lugar. Y la puedo evidenciar en términos cotidianos del trato que tenemos. No es la relación del especialista con el estudiante" (Académico 3).

Se instala acá una mirada que privilegia lo dialógico y las relaciones horizontales entre los académicos y los futuros profesores de historia. Estas relaciones con los estudiantes se plantean, también, en el marco de la actividad propiamente académica durante el semestre. Como lo señala uno de los académicos en uno de nuestros diálogos, quien al referirse a la organización pedagógica de la asignatura, y luego de una primera etapa directiva, señala que:

Después viene la etapa dialógica, y la tercera etapa participativa o productiva. La dialógica tiene que ver con los debates, los foros que se van abriendo dentro de la clase, y la parte productiva de la clase, que usted le denomina participativa, para mí es productiva, los estudiantes tienen que generar conocimiento (Académico 3).

Lo descrito nos lleva a concebir la presencia de situaciones dialógicas en la relación cotidiana de los formadores y sus estudiantes. Y también de momentos de dialogicidad en el desarrollo de actividades propiamente formativas como lo declara el docente citado. Sin embargo en la profundización de la discusión con los docentes emergió la idea del control y directividad en la relación formativa, como se plantea en el siguiente relato al describir su secuencia de formación. "una primera parte directiva, donde doy clases magistrales en un sentido de clases mal llamadas frontales, pero es para generar un horizonte de lo que se trata el semestre, esa la doy yo, directiva en su lenguaje” (Académico 2).
Desde esta misma lógica directiva, una de las académicas participantes nos señala,

Hay estudiantes que necesitan el control, la 'soga cortita' Impresionante, pero yo se los digo, y llegado un momento les digo: 'ya, ¿puedo alargar la soga?, ¿necesita que siga controlándolo?'. Y allí se genera un cambio y es más participativo. Participativo tampoco en un 100 por ciento. Hay cuestiones que yo decido, o que yo género y que la socializo, pero no hay aportes de ellos (Académica 1).

Interesante resulta señalar que esta perspectiva de las relaciones con los estudiantes está basada en un rol directivo y técnico de la relación pedagógica. Es decir, se plantea esta relación de vigilancia y control justificado en la precariedad y en la falencia del estudiante en términos de sus capacidades para enfrentar alguna de las tareas planteadas por la asignatura. De modo tal que este control se va alivianando a medida que el estudiante logra alcanzar mayor autonomía y con ello ciertas metas de aprendizaje.

\section{Discusión de resultados}

Los hallazgos encontrados -tanto en los documentos formativos como en los testimonios de los docentes a cargo de la formación inicial de profesores de historia- nos indican la existencia de una predominancia de los postulados teóricos expresados en la racionalidad técnica del currículum, en su vertiente racionalista académica, la que otorga al conocimiento disciplinar-considerado como un objeto de la cultura ilustrada y transferible a quienes no lo poseen- un valor central en el desarrollo curricular y en la comprensión de las acciones pedagógicas (Grundy 1991; Eisner y Vallance 1974; Ferrada 2004). Lo señalado va en completa tensión con las orientaciones tanto disciplinares como pedagógicas expresadas en los mismos documentos de formación y en la literatura que ha validado la incorporación de otros actores y territorios, legitimándose tópicos tales como la historia local, historia de la mujer, de la niñez, historias barriales, comunales, etc. Todos temas que, indudablemente, han venido a renovar el conocimiento y la epistemología de lo social. No obstante, estas temáticas consideradas de manera muy leve y tangencial, tienden a imponerse como contenido de carácter eminentemente académico 
con énfasis en lo disciplinar. Lo anterior nos lleva a discutir que a pesar del avance de las disciplinas pedagógicas e historiográficas, la formación de profesores de historia continúa anclada a lógicas formativas tradicionales y técnicas, como ha sido por muchas décadas, sobre todo en universidades de larga tradición como las estudiadas. Sin embargo se debe reconocer que la política pública ha intentado - por lo menos en lo declarativo- mover el foco de lo disciplinar hacia posturas más renovadas del conocimiento histórico, con énfasis en lo social e identitario (MINEDUC 2001; 2012), lo que podría acercar a las propuestas gubernamentales a las racionalidades prácticas de lo curricular en tanto enfatizan la comprensión del medio y la consideración de los contextos y los saberes de los sujetos. Lo anterior no se alcanza a posicionar como una característica que impacte en la formación de estos pedagogos, más bien genera discursos que provocan confusión y tensiones entre la política pública y los académicos encargados de la formación docente universitaria. Otra vertiente muy importante de los resultados a discutir es la referida a la posibilidad de integración del conocimiento disciplinar con el conocimiento pedagógico. A este respecto se recurre frecuentemente -por parte de las fuentes estudiadasa la categoría de transposición didáctica que es preocupación fundamental de los docentes universitarios de la preparación de pedagogos en historia. Aquí se verifica una asunción clara de los conceptos de la transformación del conocimiento del saber historiográfico, como saber sabio, al saber enseñable (Chevalard 1998), propiedad característica de una racionalidad práctica de lo curricular. Lo mismo ocurre con la presencia de la categoría del conocimiento pedagógico del contenido (Ossandón 2002). Sin embargo creemos necesario, frente a la hegemonía de estas opciones epistemológicas y disciplinares, realizar un análisis desde la didáctica de la historia y discutir, particularmente con Chevalard (1998), acerca de las reales posibilidades de aplicar el concepto de la transposición didáctica a la enseñanza de esta disciplina del conocimiento. Toda vez que la historia como disciplina de lo social, del tiempo y de la realidad social pasada y presente ha buscado, desde un tiempo hasta hoy, sus propios fundamentos didácticos (Aisenberg 1995; Carretero 2007; Carretero y Castorina 2010). De esta manera y bajo estas consideraciones discutimos si es posible transponer el conocimiento histórico a un saber transformado, no banalizado, desde las propias estructuras epistémicas y de la complejidad del saber históricosocial y sus categorías. Esto más aun, cuando efectivamente se trata como lo plantea Camilloni (en Aisenberg et al. 1995) del conocimiento de lo social y de las realidades sociales, las que tienen como propiedad epistémica ser un conocimiento provisional, de construcción contextualizada y mediatizada por experiencias intersubjetivas y comunitarias. En relación con la participación de los actores y su rol respecto del conocimiento los documentos consultados entregan un gran protagonismo al docente en su propiedad, jerarquía y distribución. Sin embargo para los académicos este es una construcción social. Dicho a propósito de la interpretación y reconstrucción que cada sujeto, como sujeto que interpreta, puede formular de un proceso histórico o social. Esto legitimaría a los actores -los profesores en formación- en tanto cada uno de ellos puede asumir u optar por distintas miradas interpretativas de la historia. Lo anterior se condice por las corrientes de racionalidades prácticas del currículum, para quienes el profesor debe promover un juicio de carácter práctico, situado, que supere las interpretaciones unívocas de las racionalidades técnicas (Schwab 1978). Sin embargo, este énfasis en la interpretación y juicio deliberativo puede generar una falsa sensación de emancipación (Grundy 1991). En este marco los testimonios de los formadores, como vimos, mencionan con claridad la propiedad del conocimiento como socialmente construido, explicado por la pluralidad de interpretaciones de lo social, lo que estaría en directa relación con la participación igualitaria, e incluso con la idea de emancipación, dicho en términos de las racionalidades críticas del currículum. Sin embargo, esta mirada de la construcción social del conocimiento sigue instalada desde las mismas disciplinas del conocimiento social. Es decir, se considera el conocimiento como socialmente construido, cuando los académicos formadores expresan la subjetividad y múltiples interpretaciones que el conocimiento histórico puede adoptar. Se hace así referencia a una de las propiedades del conocimiento social que lo destaca de otros tipos de conocimiento, pero que se mantiene de igual forma bajo una racionalidad técnica, toda vez que se plantea permanentemente bajo predominio del profesor como saber ilustrado y tributario de una perspectiva academicista. No obstante en las instancias dialógicas de tratamiento de los resultados con los actores, hemos valorado la relevancia del rol transformador del conocimiento 
social e histórico y su presencia como eje en la formación de los profesores de historia. Respecto de los estudiantes y su rol en la construcción de conocimiento, estos asumirían un rol caracterizado por las racionalidades técnicas del currículum, las descritas en la literatura al respecto (Grundy 1991; Ferrada 2004; Pascual 1998), en este sentido el estudiante asume un rol pasivo y de receptor de conocimientos, en espera que el profesor pueda entregárselo. Esta postura es muy criticada por los docentes universitarios, quienes la califican incluso de ser una postura ya naturalizada del estudiante/ profesor en formación en su rol de receptor de conocimientos, no siendo parte activa de su producción. Lo anterior genera una mirada negativa hacia ellos, ya que esta postura dista mucho de esta autonomía y participación activa que reclaman los formadores al estudiante, propia de una racionalidad crítica del currículum, en donde una de las disposiciones más importantes justamente es esta toma de conciencia y trabajo activo que deben tener los actores, en particular quienes toman conciencia de su opresión (Freire 2014; Pascual 1998). Develamos, así, una tensión importante radicada en las declaraciones de dialogicidad y horizontalidad manifestada por los académicos al momento de caracterizar la relación pedagógica con los profesores en formación. Sin embargo en el desarrollo y profundización de su comprensión, podemos apreciar que las formas de relacionarse con los sujetos estudiantes se mueven en un marco de verticalidad y control del docente. Tal es el caso de una característica muy mencionada en nuestras conversaciones con los académicos formadores, en orden a establecer con los estudiantes un tipo de relación basada en la jerarquía y énfasis de la autoridad, justificada en la precariedad y en la falencia de ellos respecto de sus capacidades para enfrentar alguna de las tareas planteadas en el proceso formativo.

\section{Conclusiones}

El actual panorama de la formación de profesores de historia en Chile nos presenta variadas tensiones y nudos críticos. Uno de los más relevantes radica en la hegemonía incontrarrestable del conocimiento disciplinar historiográfico, el que es visto desde una perspectiva tradicional y con un marcado acento en lo cronológico y en visiones tradicionales del conocimiento de lo social. A lo anterior se agregan orientaciones de política pública confusas y contradictorias en sus postulados pedagógicos y disciplinares. Todo ello ha llegado a fundar una identidad eminentemente disciplinar en los sujetos que actúan en el proceso formativo -en particular desde los académicos formadores-, la que se extiende posteriormente como piedra angular de la identidad del ejercicio profesional de los profesores de historia. Lo señalado nos lleva a plantear que la actualidad de la formación de profesores de historia se entiende como una serie de acciones destinadas a la transmisión de saberes académicos distribuidos y hegemonizado por el profesor en el marco de una concepción unidireccional de las relaciones pedagógicas entre los actores de la formación. A este respecto enfrentamos ciertas tensiones y controversias que la producción de conocimiento respecto de la formación inicial de profesores de historia -en un panorama de casi inexistencia- no ha respondido aún. Finalmente, concluimos que la realidad descrita ha dejado a los académicos formadores atrapados en sus propias concepciones y ante la necesidad de enfrentarse a una política de FID, que muchas veces entra en tensión consigo misma y con las propias directrices de las instituciones formativas.

\section{Referencias Citadas}

Cáceres, $\mathrm{P}$.

2003 Análisis cualitativo de contenido. Una alternativa metodológica alcanzable. En: Psicoperspectivas. Revista de la Escuela de Psicología. Facultad de Filosofía y Educación. Pontificia Universidad Católica de Valparaíso, 2: pp. 52-83.

Camilloni, A.

1995 Epistemología de la didáctica de las ciencias sociales. En: Didáctica de las Ciencias Sociales. Aportes y Reflexiones, editado por B. Aisemberg, S. Alderoqui, pp. 25-41. Paidós Educador, Buenos Aires.

Carretero, $\mathrm{M}$.

2007 Documentos de Identidad. Buenos Aires: Paidós.
Carretero, M. Castorina, J.

201 La Construcción Del Conocimiento Histórico. Paidós. Buenos Aires.

Cisternas, $\mathrm{T}$.

2011 La investigación sobre formación docente en Chile. Territorios explorados e inexplorados. Revista Calidad en la Educación 35: 131-164.

Chevalard, I.

1998 La Transposición Didáctica. Aique Editores. Argentina: Da Silva, T.

1999 Documentos de Identidad. Una introducción a las teorías del currículo. Autentica Editorial. Belo Horizonte. 
Eisner, E. y Wallance E.

1974 Five conception of curriculum: Their roots and implication of curriculum planning. En: Eisner E. $y$ Wallance E. Conflictig conception of curriculum. Bekerley Mc Cutchan Publishing Company, pp. 1-18.

Freire, $\mathrm{P}$.

2014 Pedagogía del Oprimido. $1^{\text {a }}$ edición (especial). Siglo XXI. Buenos Aires.

Ferrada, D.

2002 Currículum crítico comunicativo. El Roure. Barcelona.

Ferrada, D.

2004 Perspectivas y enfoques curriculares. La necesidad de una nueva organización. Cuadernos de Pedagogía. Universidad Arcis. Santiago, 13: 29-58.

Ferrada, D., Turra, O.

2012 Las comunidades de profesores como agentes legítimos en la construcción curricular para la formación inicial. Paulo Freire. Revista de Pedagogía Crítica, Universidad Academia de Humanismo Cristiano. Santiago, 11:207-217.

Ferrada, D., Villena, A. y Turra, O.

2015 Transformar la Formación. Las Voces del Profesorado. RIL Editores. Santiago, Chile.

Grundy, S.

1991 Producto o praxis del curriculum. Ediciones Morata. Madrid.

Habermas, J.

1986 Conocimiento e interés. Taurus. Madrid.

Lara, M., Förster, C. y Gorichon, S.

2007 Transferencia de la investigación educacional a la formación inicial de profesores. Revista Calidad en la Educación, 27: 178-204.

Magendzo, A.

200 Dilemas del curriculum y la pedagogía. Analizando la reforma curricular desde una perspectiva crítica. LOM Ediciones. Santiago, Chile.

Malagón, L.

2008 El currículo: perspectivas para su interpretación. En: Investigación y Educación en Enfermería, vol. XXVI, núm. 2, septiembre, 2008, pp. 136-142, Universidad de Antioquia Medellín, Colombia.

MINEDUC

2001 Estándares De desempeño para la formación inicial de docentes. Santiago, Chile: Ministerio de Educación.
MINEDUC

2005 Informe Comisión sobre Formación Inicial Docente. Santiago, Chile: Ministerio de Educación.

MINEDUC

2006 Informe Consejo Asesor Presidencial para la Calidad de la Educación. Santiago: Ministerio de Educación.

\section{MINEDUC}

2012 Estándares Orientadores para las carreras de pedagogía en educación media. Ministerio de Educación. Santiago, Chile.

Osandón, L.

2002 De las distintas formas de aproximarse al panorama de la didáctica de las ciencias sociales. Una propuesta de lectura al problema. En: Pensamiento Educativo, 30. Pontificia Universidad Católica de Chile, pp. 139-175.

Pascual, E.

1998 Racionalidades En La Producción Curricular y el Proyecto Curricular En: Pensamiento Educativo, 23. Pontificia Universidad Católica de Chile, pp. 13-72.

Rodríguez, J.; Gil, J. y García, E.

1999 Metodología de la investigación cualitativa. Aljibe. Málaga.

Santibáñez, C.

2013 Profesores de historia e historiografía estatista: Consideraciones básicas para los estudiantes de Pedagogía en Historia, En: Estudios Pedagógicos, XXXIX (1), Universidad Austral de Chile. Valdivia, pp. 403-416.

Schwab, J.

1974 Un enfoque práctico para la planificación del currículum. El ateneo. Buenos Aires.

Shulman, L.

2001 Conocimiento y Enseñanza. En: Revista Estudios Públicos, 83, pp. 163-196.

Valdés, $\mathrm{M}$.

2017 Racionalidades curriculares y perspectivas didácticas en la formación inicial de profesores de historia. Un estudio desde universidades regionales del sur de Chile. Tesis de Doctorado en Educación Universidad Academia de Humanismo Cristiano, Santiago de Chile.

Vásquez, $\mathrm{N}$.

2005 La formación del profesorado de historia en Chile. La formación inicial y permanente de los educadores de la $\mathrm{V}$ Región en el marco de la Reforma Educacional, Tesis de Doctorado en didáctica de las Ciencias Sociales, Universitat de Barcelona. 